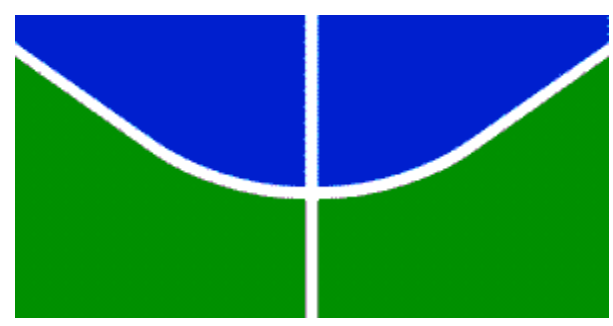

UNIVERSIDADE DE BRASÍLIA

Faculdade de Agronomia e Medicina Veterinária

Programa de Pós-Graduação em Saúde Animal

\title{
EFEITOS DO PERÍODO DE MATURAÇÃO DE QUEIJOS SOBRE A MICROBIOTA DETERIORANTE E LISTERIA MONOCYTOGENES
}

ANDERSON JOAQUIM PEREIRA DOS SANTOS

DISSERTAÇÃO DE MESTRADO EM SAÚDE ANIMAL 


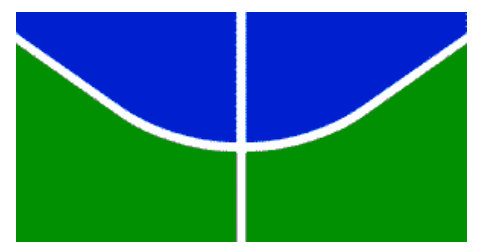

UNIVERSIDADE DE BRASÍLIA

Faculdade de Agronomia e Medicina Veterinária

Programa de Pós-Graduação em Saúde Animal

\title{
EFEITOS DO PERÍODO DE MATURAÇÃO DE QUEIJOS SOBRE A MICROBIOTA DETERIORANTE E LISTERIA MONOCYTOGENES
}

\author{
ANDERSON JOAQUIM PEREIRA DOS SANTOS \\ ORIENTADOR: PROF(A). DRA. MÁRCIA DE AGUIAR FERREIRA \\ DISSERTAÇÃO DE METRADO EM SAÚDE ANIMAL
}

PUBLICAÇÃO: $128 / 2016$

BRASÍLIA/DF

MAIO/2016 


\section{REFERÊNCIA BIBLIOGRÁFICA E CATALOGAÇÃO}

SANTOS, A. J. P. Efeitos do período de maturação de queijos sobre a microbiota deteriorante e Listeria monocytogenes Brasília: Faculdade de Agronomia e Medicina Veterinária, Universidade de Brasília, 2016, 36 p. Dissertação de Mestrado.

Documento formal, autorizando reprodução desta dissertação de mestrado para empréstimo ou comercialização, exclusivamente para fins acadêmicos, foi passado pelo autor à Universidade de Brasília e acha-se arquivado na Secretaria do Programa. O autor reserva para si os outros direitos autorais, de publicação. Nenhuma parte desta dissertação de mestrado pode ser reproduzida sem a autorização por escrito do autor. Citações são estimuladas, desde que citada a fonte.

Santos, Anderson Joaquim Pereira

Efeitos do período de maturação de queijos sobre a microbiota deteriorante e Listeria monocytogenes. / Anderson Joaquim Pereira dos Santos; Orientação de Márcia de Aguiar Ferreira. - Brasília, 2016.

36 p. : il.

Dissetação de Mestrado (M) - Universidade de Brasília / Faculdade de Agronomia e Medicina Veterinária, 2016.

1. Micro-organismos patogênicos. 2. Queijos artesanais. 3. Produção de queijos. 4. Coliformes. 5. Escherichia coli. I. Ferreira, M. A. II. Efeitos do período de maturação de queijos sobre a microbiota deteriorante e Listeria monocytogenes. 


\title{
UNIVERSIDADE DE BRASÍLIA
}

\section{EFEITOS DO PERÍODO DE MATURAÇÃO DE QUEIJOS SOBRE A MICROBIOTA DETERIORANTE E LISTERIA MONOCYTOGENES}

\author{
ANDERSON JOAQUIM PERERIA DOS SANTOS
}

Dissertação de Mestrado submetida ao programa de pós-graduação em Saúde Animal, como parte dos requisitos necessásios à obtenção do grau de Mestre em Saúde Animal

APROVADA POR:

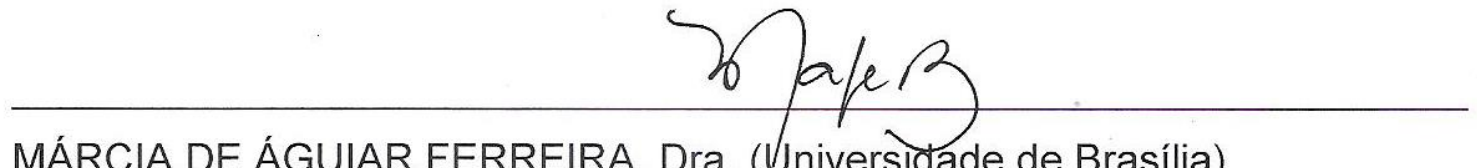

MÁRCIA DE ÁGUIAR FERREIRA, Dra. (Universłơde de Brasília)

Orientadora

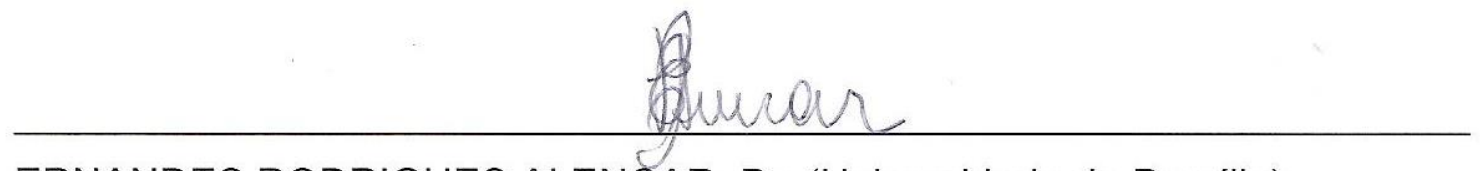

ERNANDES RODRIGUES ALENCAR, Dr. (Universidade de Brasília)

Examinador Externo

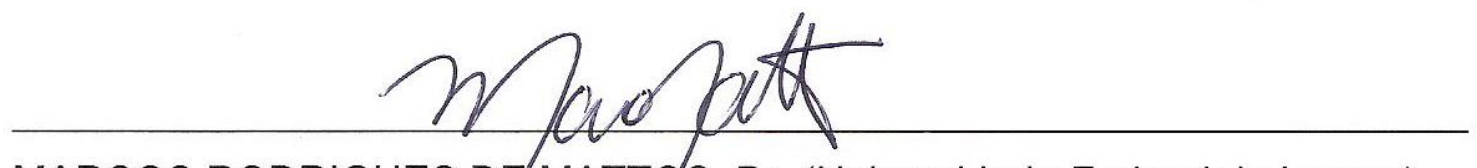
MARCOS RODRIGUES DE MATT $\varnothing S$, Dr. (Universidade Federal de Lavras) Examinador Externo

BRASÍLIA, 13 DE MAIO DE 2016. 
Dedico este trabalho aos meus pais, Edivá e Maria Laide, e à minha noiva, Amanda, que sempre estiveram do meu lado acreditando em meus sonhos e muitas vezes sonhando comigo. 


\section{AGRADECIMENTOS}

Agradeço primeiramente à Deus, por tudo que eu conquistei e que ainda vou conquistar.

À minha família, minha base e motivação para tudo.

À Amanda, minha noiva, que sempre está ao meu lado e é e sempre foi a minha maior encorajadora.

À minha orientadora Prof ${ }^{a}$. Drª . Márcia de Aguiar Ferreira por estar sempre disponível a ensinar e pelo exemplo de pessoa e profissional.

À Jaqueline Lamounier por me auxiliar sempre dando suporte no laboratório.

Ao técnico Márcio e ao professor Borgo da FAV-UnB por me auxiliar e emprestar o laboratório de análises de alimentos.

Ao setor de produção de leite da FAL/UnB por ceder a matéria prima utilizada para elaboração deste trabalho.

À Cap-Lab e Associação Brasileira das Indústrias de Queijo (ABIQ) por fornecerem materiais utilizados nesse experimento. 


\section{RESUMO}

Com o objetivo de verificar o efeito do período de maturação sobre o desenvolvimento de microorganismos foram realizados dois estudos, sendo o primeiro a partir da produção de queijos com leite cru (n=7) para avaliação das contagens de micro-organismos aeróbios mesófilos, coliformes totais e Escherichia coli, e o segundo com queijos fabricados com leite laboratorialmente esterilizado ( $\mathrm{n}=7)$, para avaliação das contagens de Listeria monocytogenes inoculada. Em ambos os estudos, os queijos foram maturados em condições de temperatura (7,5 $\left.\pm 1,5{ }^{\circ} \mathrm{C}\right)$ e umidade $(45 \pm 5 \%)$ controladas, durante 60 dias. Foram realizadas análises da matéria prima (leite cru e leite esterilizado), da massa imediatamente após a produção, dos queijos no primeiro dia (dia 01) e a cada dez dias (dias 10, 20, 30, 40, 50 e 60); também foram determinados os teores de umidade desses queijos. Aeróbios mesófilos apresentaram contagens de 5,77 log UFC/mL no leite, 6,67 log UFC/g na massa, 8,92 log UFC/g com vinte dias de maturação, quando alcançou sua contagem máxima e 7,24 log UFC/g aos sessenta dias de maturação. As contagens de coliformes totais foram: 5,47 log UFC/mL no leite, 6,33 log UFC/g na massa, 7,73 log UFC/g aos dez dias de maturação, quando alcançou sua contagem máxima e 5,18 $\log \mathrm{UFC} / \mathrm{g}$ aos sessenta dias. E. coli apresentou contagens de 2,52 $\log \mathrm{UFC} / \mathrm{mL}$ no leite, 3,48 log UFC/g na massa, 5,19 log UFC/g com vinte dias, quando alcançou sua contagem máxima e 2,30 log UFC/g aos sessenta dias de maturação. As contagens de L. monocytogenes foram de 6,50 log UFC/g na massa, 8,09 log UFC/g no trigésimo dia, quando alcançou sua contagem máxima e 7,66 log UFC/g aos sessenta dias de maturação. Com os resultados obtidos foi possível concluir que o período de maturação de 60 dias não foi suficiente para garantir a higiene e a inocuidade dos queijos considerando o comportamento dos micro-organismos estudados sob as condições e os tempos analisados.

Palavras-chaves: Micro-organismos patogênicos; Queijos artesanais; Produção de queijos; Coliformes; Escherichia coli. 


\begin{abstract}
In order to verify the effect of the maturation period on the development of micro-organisms two studies were conducted, in which the first one was developed with cheeses produced with raw milk $(\mathrm{n}=7)$ for evaluation of aerobic microorganisms mesophilic counts, total coliforms and Escherichia coli, and the second one with cheeses produced with laboratorial sterilized milk $(\mathrm{n}=7)$ for the assessment of the counts of Listeria monocytogenes inoculated. In both studies, the cheeses were matured under controlled conditions of temperature $\left(7.5 \pm 1.5^{\circ} \mathrm{C}\right)$ and humidity (45 $\pm 5 \%$ ), for 60 days. Analysis of the prime materials (raw milk and sterilized milk), the curd immediately after production, the cheeses on the first day (Day 01) and every ten days (days 10, 20, 30, 40, 50 and 60) were carried out; Also, the cheeses' moisture were estimated. Mesophilic aerobic counts were 5.77 CFU/mL log in milk sample, $6.67 \mathrm{log} \mathrm{CFU} / \mathrm{g}$ in curd sample, $8.92 \log$ CFU/g in cheese sample within twenty days of ripening, when it reached its maximum count and 7.24 $\log \mathrm{CFU} / \mathrm{g}$ at the sixtieth day of ripening. Total coliform counts were: $5.47 \log$ CFU/mL in milk sample, $6.33 \mathrm{log}$ CFU/g in curd sample, $7.73 \mathrm{log}$ CFU/g on the tenth day of ripening, when it reached its maximum count and $5.18 \log \mathrm{CFU} / \mathrm{g}$ at the sixtieth day. $E$. coli showed counts of $2.52 \log \mathrm{CFU} / \mathrm{mL}$ in milk sample, $3.48 \mathrm{log} \mathrm{CFU} / \mathrm{g}$ in curd sample, 5.19 $\log \mathrm{CFU} / \mathrm{g}$ with twenty days of ripening when reached its maximum count and $2.30 \mathrm{log} \mathrm{CFU} / \mathrm{g}$ at the sixtieth day of ripening. L. monocytogenes counts were $6.50 \mathrm{log} \mathrm{CFU} / \mathrm{g}$ in curd sample, $8.09 \log \mathrm{CFU} / \mathrm{g}$ on the thirtieth day, when it reached its maximum count and $7.66 \mathrm{log} \mathrm{CFU} / \mathrm{g}$ within sixty days of ripening. With the results it was concluded that the 60-day maturation period was not enough to ensure the hygiene and safety of cheeses considering the behavior of microorganisms studied under the circumstances analyzed.
\end{abstract}

Keywords: Pathogenic microorganisms; Artisanal cheeses; Cheese production; coliforms; Escherichia coli. 


\section{LISTA DE ILUSTRAÇÕES}

Figura 1 Efeito visual da perda de umidade ao longo dos 60 dias de maturação. 


\section{LISTA DE TABELAS}

Tabela 1 Contagens médias de aeróbios mesófilos, coliformes totais, Escherichia coli e teores de umidade de queijos produzidos com leite cru e maturados por 60 dias em condições controladas de umidade e de temperatura. 


\section{LISTA DE GRÁFICOS}

Gráfico 2 Contagens de L. monocytogenes (UFC/g) inoculada e teores de umidade $(\%)$ de queijos maturados por 60 dias em condições controladas de umidade e de temperatura. 


\section{LISTA DE ABREVIATURAS E SIGLAS}

\begin{tabular}{ll}
${ }^{\circ} \mathrm{C}$ & Graus Celcius \\
${ }^{\circ} \mathrm{D}$ & Graus Dornic \\
${ }^{\circ} \mathrm{H}$ & Graus Hortvet \\
a.C & Antes de Cristo \\
Aa & Atividade de água \\
ANVISA & Agência Nacional de Vigilância Sanitária \\
Cepa & Conselho Estadual de Política Agrícola \\
E. coli & Escherichia coli \\
ESD & Extrato Seco Desengordurado \\
EUA & Estados Unidos da América \\
FAL/UnB & Fazenda Água Limpa/Universidade de Brasília \\
g & Grama \\
L. grayi & Listeria grayi \\
L. innocua & Listeria innocua \\
L. ivanovii & Listeria ivanovii \\
L. monocytogenes & Listeria monocytogenes \\
L. seeligeri & Listeria seeligeri \\
L. welshimeri & Listeria welshimeri \\
LABLEITE/FAV/UnB & Laboratório de Análises de Leite e Derivados/Faculdade de \\
& Agronomia e Medicína Veterinária/Universade de Brasília \\
LEB & Listeria Enrichment Broth \\
MAPA & Ministério da Agricultura, Pecuária e Abastecimento \\
mL & Mililitro \\
RDC & Resolução da Diretoria Colegiada \\
RIISPOA & Regulamento da Inspeção Industrial e Sanitária de Produtos de \\
& Origem Animal \\
TSA & Triptone Soya Agar \\
UFC & Unidade Formadora de Colônia \\
& \\
\hline &
\end{tabular}




\section{SUMÁRIO}

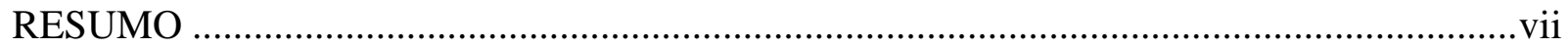

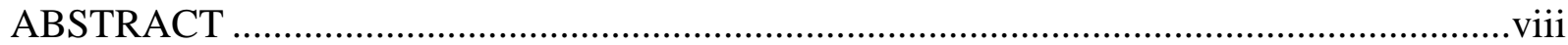

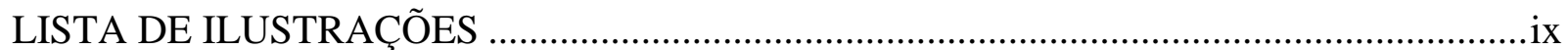

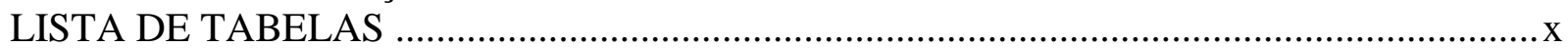

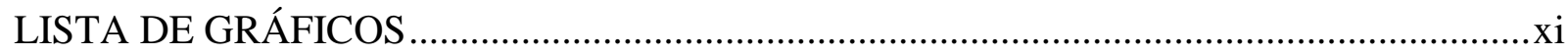

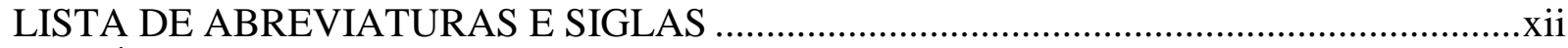

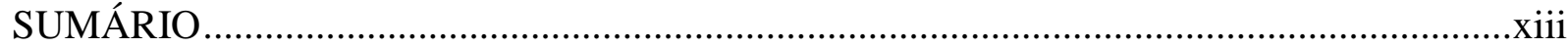

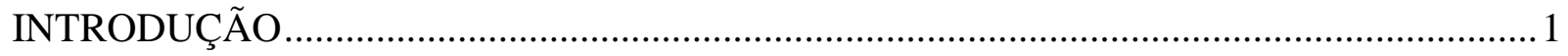

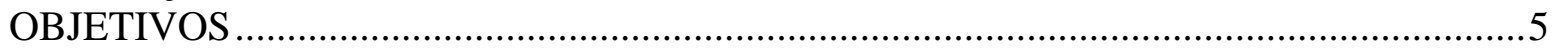

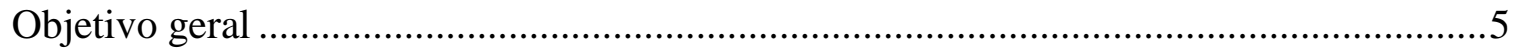

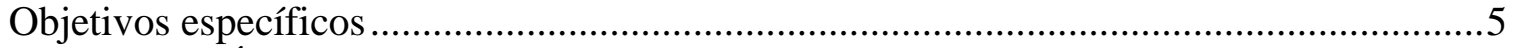

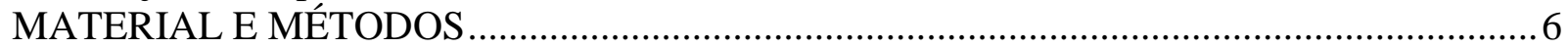

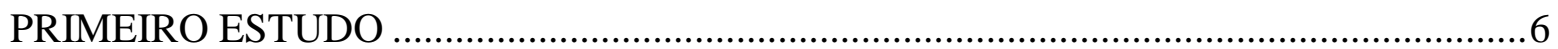

Produção e maturação dos queijos produzidos com leite cru ........................................6

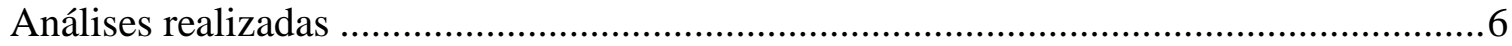

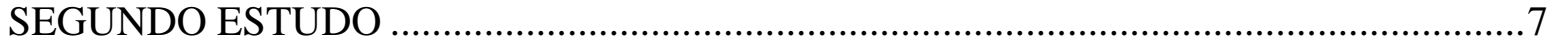

Inóculo, produção e maturação dos queijos inoculados com Listeria monocytogenes .......7

Análises microbiológicas..............................................................................

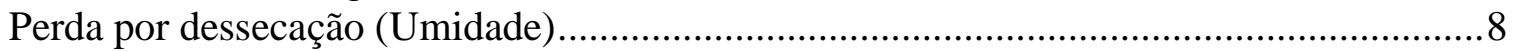

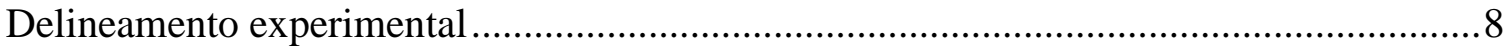

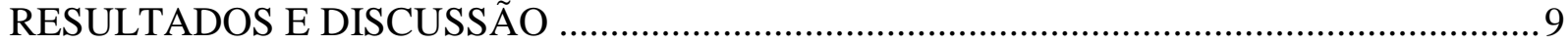

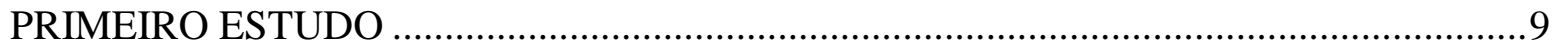

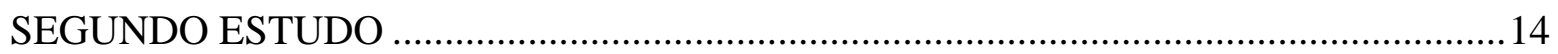

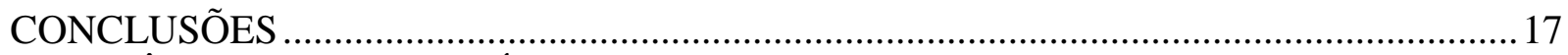

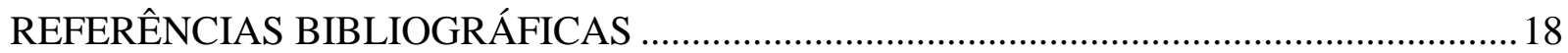




\section{INTRODUÇÃO}

Os queijos são, em geral, produtos muito manipulados e, por este motivo, passíveis de contaminação durante a fabricação, especialmente de origem microbiológica (PINTO et al, 2009). Queijos produzidos a partir de leite cru ou em condições de higiene insatisfatórias, podem se tornar impróprios para o consumo (APHA, 1947; LEITE, 2012; PINTO, 1996). A ingestão de queijos contaminados pode ocasionar diversas doenças, desde zoonoses, como brucelose e tuberculose, até intoxicações e infecções alimentares.

Atualmente, a produção de queijos tradicionais em diversas regiões do Brasil, tem sido objeto de pesquisas principalmente, por ser a partir de leite cru, o que requer cuidados em todas as etapas da produção para que seja garantida a inocuidade dos produtos e a saúde dos consumidores (SOARES, 2014; BORGES, et al., 2003). De acordo com o Regulamento Técnico de Identidade e Qualidade de Queijos (RTIQQ) da Portaria No 146/1996 do Ministério da Agricultura, Pecuária e Abastecimento (MAPA), queijos produzidos com leite cru só podem ser comercializados após 60 dias de maturação (BRASIL, 1996).

Por outro lado, os queijos artesanais produzidos no estado de Minas Gerais atendem a legislação específica do estado, Lei No 20.549/2012 (MINAS GERAIS, 2012). A Portaria No 1305/2013 do Instituto Mineiro de Agropecuária (IMA), estabelece que o período mínimo de maturação do queijo Minas artesanal é de 17 dias para a microrregião do Serro e mínimo de 22 dias paras as microrregiões da Canastra, do Cerrado, de Araxá e do Campo das Vertentes, até que novas pesquisas sejam realizadas e alterem os tempos de maturação (MINAS GERAIS, 2013). Durante esse período, no qual acontece a maturação, a temperatura e a umidade são fatores importantes, tendo em vista que influenciam a atividade de água, fundamental para o crescimento bacteriano (DORES et al, 2012).

Os queijos artesanais são produzidos em queijarias credenciadas no estado de Minas Gerais com base em receitas passadas de geração para geração, e que são caracterizadas pela utilização do pingo, fermento endógeno coletado da dessora da produção de queijos do dia anterior (MARTINS, 
2006; DORES et al., 2012). Já os queijos informais não passam por nenhum tipo de controle de qualidade, sendo normalmente comercializados em pequenas propriedades rurais, em feiras e por vendedores ambulantes (MENESES et al., 2012; AMORIM et al., 2014).

No ano de 2013, nos Estados Unidos, 10\% dos surtos de origem alimentar tiveram procedência de leite e seus derivados, sendo $81 \%$ originários de produtos que não passaram por nenhum processo de pasteurização (CDC, 2015). Diversas pesquisas sobre a qualidade microbiológica de queijos, principalmente o tipo Minas, relatam a ocorrência de microorganismos patogênicos em números que excedem os limites estabelecidos pela legislação. Dentre as bactérias patogênicas detectadas, destacam-se Staphylococcus aureus, Salmonella spp, Campylobacter spp., Escherichia coli e Listeria monocytogenes (MUNGAI et al, 2015; GOULD et al, 2014; AMORIM et al, 2014; ANTONELLO et al., 2012; SENGER 2011; FERNANDES et al., 2011; SCHMITT et al., 2011; RESENDE, 2010; MELO et al., 2009; MAGALHÃES, 2007; BRANT et al., 2007; BARCELLOS 2006; ARRUDA 2006; FEITOSA et al., 2003). De acordo com Castro, 2015, a fabricação de queijo Minas artesanal utilizando leite não pasteurizado favorece a multiplicação de bactérias potencialmente patogênicas e/ou suas toxinas, representando importante questão de saúde pública.

Os alimentos sãos os principais agentes veiculadores de micro-organismos do genêro Listeria spp., sendo L. monocytogenes a principal espécie por ser patogênica para humanos e diversos animais. Uma importante característica desta espécie é a capacidade de se multiplicar em temperaturas de refrigeração, entre 2 e $4{ }^{\circ} \mathrm{C}$, e de sobreviver por mais de 100 dias a $4{ }^{\circ} \mathrm{C}$. O patógeno, também é capaz de se multiplicar em intervalos de temperatura entre 2,5 e $44{ }^{\circ} \mathrm{C}$ e em concentrações salinas de 10,5 até 30,5\%; o intervalo de pH ótimo é de 6 a 8 , entretanto essa bactéria pode crescer entre 5 e 9 , além de ser capaz de se desenvolver em alimentos com baixa atividade de água (até 0,83 Aa) (CRUZ et al. 2008; JAY, 2005).

Os queijos, entre os derivados lácteos são os que apresentam maiores ocorrências de contaminação por L. monocytogenes, principalmente os de alta e de média umidade. A presença dessa bactéria nesses queijos é preocupante porque são produtos que podem ser armazenados por períodos relativamente longos em refrigeração, o que permite o seu desenvolvimento, além de serem alimentos prontos para o consumo (BARANCELLI, 2011a).

Os parâmetros de qualidade microbiológica para o leite cru destinado à produção de queijos artesanais mineiros foram estabelecidos pela Lei Estadual $N^{\circ}$ 14.185/2002 (MINAS GERAIS, 
2002), que foi revogada pela Lei Estadual No 20.549/2012 (MINAS GERAIS, 2012), que dispõe sobre a produção e a comercialização dos queijos artesanais de Minas Gerais, porém não estabelece critérios de qualidade para a matéria prima (leite cru) ou para os queijos. Conforme o Artigo 26 dessa mesma legislação, estudos técnico-sanitários deverão ser realizados em queijarias no Estado, garantindo a participação de representantes de produtores de queijos artesanais, para serem posteriormente, submetidos à apreciação de câmara específica do Conselho Estadual de Política Agrícola - CEPA, a fim de subsidiar, para cada tipo ou variedade de queijo, a regulamentação de parâmetros físico-químicos e microbiológicos; de prazos de validade e de maturação, quando couber; das características técnicas das instalações, dos equipamentos e dos utensílios; e, das boas práticas de fabricação e higiene operacional.

Altas contagens bacterianas no leite usado na elaboração do queijo além de exercer influência sobre as características sensoriais e o tempo de prateleira do produto, elevam a probabilidade de veiculação de doenças (MACHADO, 2008). O leite cru representa uma importante fonte de bactérias desejáveis para a produção de queijo artesanal (FEUTRY et al., 2012). Entretanto, também pode contaminar o queijo com micro-organismos patogênicos e/ou deteriorantes, desencadeando problemas como estufamento precoce, falta de uniformidade do produto final e presença de toxinas, o que pode trazer risco à saúde de quem o consome (GONZÁLEZ et al., 2003; LAW e TAMIME, 2010).

A maturação de queijos é a fase em que ocorrem as transformações físicas, bioquímicas e microbiológicas que se processam no interior da massa, sob a ação de enzimas lipolíticas e proteolíticas, a maior parte de origem microbiana, sendo um fenômeno bastante complexo que varia de queijo para queijo (MARTINS, 2006).

Segundo Ordónez (2005) as principais reações bioquímicas que ocorrem no queijo durante a maturação são: glicólise, proteólise, lipólise, sendo que as duas últimas afetam a textura, sabor e aroma finais do produto.

De acordo com Martins (2006) o processo de maturação depende de fatores como temperatura e umidade do ambiente; composição química da coalhada e da microbiota residual da coalhada.

Apesar do esforço de diversos organismos em melhorar o processamento dos derivados de leite, as pesquisas acadêmicas ainda são insuficientes para se chegar a um consenso quanto às características físico-químicas e microbiológicas dos queijos artesanais (CASTRO, 2015). É 
necessário compreender os efeitos da maturação sobre as características microbiológicas de queijos tipo Minas, pois ainda não estão completamente esclarecidos na literatura. Apesar de existir legislações que determinam períodos mínimos de maturação ainda há divergências entre as legislações federal e estadual, quanto aos critérios de qualidade e de segurança que garantam a sua inocuidade para o mercado consumidor (MARTINS, 2006).

Com base no exposto, os objetivos desta pesquisa foram de, a partir de dois estudos, analisar os efeitos da maturação de queijos fabricados com leite cru sobre a microbiota autóctone composta por aeróbios mesófilos, coliformes totais e E. coli e, a influência sobre as contagens de $L$. monocytogenes inoculada. 


\section{OBJETIVOS}

\section{Objetivo geral}

- Avaliar o efeito do período de maturação de queijos sobre o desenvolvimento de micro-organismos deteriorantes e patogênicos.

\section{Objetivos específicos}

- Avaliar os efeitos do período de maturação por 60 dias de queijos produzidos com leite cru sobre micro-organismos deteriorantes, naturalmente presentes no alimento, por meio da enumeração de aeróbios mesófilos, coliformes totais e Escherichia coli.

- Avaliar os efeitos do período de maturação por 60 dias sobre o desenvolvimento de Listeria monocytogenes inoculada intencionalmente em queijos. 


\section{MATERIAL E MÉTODOS}

\section{PRIMEIRO ESTUDO}

Esse estudo teve como objetivo avaliar o efeito do período de maturação por 60 dias sobre as contagens de microbiota autóctone, composta por micro-organismos aeróbios mesófilos, coliformes totais e E. coli, em queijos produzidos com leite cru, que foi coletado do tanque de resfriamento da Fazenda Água Limpa (FAL/UnB), acondicionado em recipientes plásticos e transportado refrigerado para o Laboratório de Análises de Leite e Derivados (LABLEITE/FAV/UnB).

\section{Produção e maturação dos queijos produzidos com leite cru}

Para a fabricação dos queijos, todos os utensílios utilizados foram previamente esterilizados e cinco litros de leite cru foram aquecidos até $40^{\circ} \mathrm{C}$, adicionando-se $50 \mathrm{~g}$ de Cloreto de Sódio e 1,5 $\mathrm{mL}$ de coagulante Quimase (Docina Nutrição LTDA) diluídos em 5,0 mL de água destilada, conforme recomendações do fabricante. Após a formação do coágulo, realizou-se o corte e a dessoragem da massa que foi dividida em porções para enformagem, resultando em sete queijos com peso aproximado de $120 \mathrm{~g}$ cada.

O processo de maturação ocorreu em câmara climática em condições controladas de temperatura $\left(7,5 \pm 1,5^{\circ} \mathrm{C}\right)$ e de umidade $(45 \pm 5 \%)$, durante sessenta dias; os queijos foram avaliados imediatamente após a fabricação (massa), após 24 horas (dia 1) e a cada 10 dias (dia 10, dia 20, dia 30, dia 40, dia 50, dia 60).

\section{Análises realizadas}

Para avaliação da qualidade da matéria prima foram realizadas análises físico-químicas para determinação dos teores de gordura, extrato seco desengordurado, lactose, densidade e proteína em 
equipamento ultrassônico Ekomilk®; da acidez pelo método quantitativo Dornic (BRASIL, 2006) e o índice crioscópio utilizando equipamento crioscópio LAKTRON.

Para as análises microbiológicas, o leite cru foi homogeneizado e submetido a diluições decimais seriadas em solução salina a $0,85 \%$; da massa e dos queijos foram coletados 5,0 gramas que eram acondicionados em sacos plásticos estéreis contendo $45 \mathrm{~mL}$ de água peptonada a $2 \%$ (Buffered Peptone Water (ISO), CM 1049, Oxoid), correspondendo à diluição 1:10, e após a homogeneização foram realizadas diluições subsequentes.

Foram realizadas contagens de aeróbios mesófilos utilizando o sistema Petrifilm ${ }^{\mathrm{TM}}$ AC ( $3 \mathrm{M}$ Microbiology, St. Paul, MN, USA) conforme recomendações do fabricante, contagens de coliformes totais e de E. coli utilizando as placas Rida ${ }^{\circledR}$ Count Coliform/E.Coli (R-Biopharm AG, Alemanha) também seguindo as recomendações do fabricante. Todas as amostras foram semeadas em triplicata e os resultados médios foram convertidos em log na base 10 e expressos em unidades formadoras de colônia por grama $(\mathrm{UFC} / \mathrm{mL} / \mathrm{g})$.

\section{SEGUNDO ESTUDO}

Esse estudo objetivou avaliar o comportamento de Listeria monocytogenes inoculada em queijos submetidos a processo de maturação por 60 dias.

\section{Inóculo, produção e maturação dos queijos inoculados com Listeria monocytogenes}

Para o preparo do inóculo utilizou-se a cepa Listeria monocytogenes Scott A 49594, que foi previamente recuperada em ágar TSA (Triptone Soya Agar - Himedia®). O inóculo foi preparado em solução salina $0,85 \%$ de forma a obter-se grau de turvação correspondente ao tubo 1 da escala nefelométrica de McFarland (Nefelobac ${ }^{\circledR}$, Probac do Brasil), contendo aproximadamente, 3,0x10 8 $\mathrm{UFC} / \mathrm{mL}$.

Para a produção dos queijos, três litros de leite pasteurizado tipo A foram esterilizados laboratorialmente, por fervura (aquecidos até $96^{\circ} \mathrm{C}$ ); após resfriamento a $40^{\circ} \mathrm{C}$ adicionou-se 3,0 $\mathrm{mL}$ de Cloreto de Cálcio, 1,5 mL de Ácido Lático, 1,8 mL de coagulante Quimase, conforme preconizado pelo fabricante (Docina Nutrição LTDA) e 30 g de Cloreto de Sódio. Após 40 minutos de repouso em estufa a $35^{\circ} \mathrm{C}$ e formação do coágulo, realizou-se o corte e a dessoragem da massa por prensagem retirando-se o máximo de soro possível; em seguida, adicionou-se $5 \mathrm{~mL}$ do inóculo de L. monocytogenes à massa, para que a contagem inicial fosse de aproximadamente 6,48 log 
UFC/g. A massa foi dividida em sete alíquotas, de aproximadamente $120 \mathrm{~g}$ cada, que foram enformadas.

O processo de maturação foi conduzido em condições controladas de temperatura $(7,5 \pm$ $1,5^{\circ} \mathrm{C}$ ) e de umidade (45 $\pm 5 \%$ ); os queijos foram avaliados no dia seguinte à produção (dia 1 ) e a cada 10 dias (dia 10, dia 20, dia 30, dia 40, dia 50, dia 60).

\section{Análises microbiológicas}

Para a enumeração de L. monocytogenes, após cada período de maturação, 5,0 g dos queijos foram transferidos para saco plástico estéril contendo $45 \mathrm{~mL}$ de Listeria Enrichment Broth (LEB) e homogeneizados para a realização de diluições decimais seriadas. As semeaduras foram realizadas em placas contendo ágar TSA (Triptone Soya Agar - Himedia®), por superfície, em triplicata e com incubação a $35^{\circ} \mathrm{C}$ por 24 horas. Os resultados médios foram convertidos em log na base 10 e expressos em unidades formadoras de colônia por grama (UFC/g).

\section{Perda por dessecação (Umidade)}

Os teores de umidade dos queijos nos dois estudos foram determinados pelo método de secagem em estufa a $105^{\circ} \mathrm{C}$ até atingir peso constante (IAL, 2004); todas as amostras foram analisadas em triplicata.

\section{Delineamento experimental}

Adotou-se delineamento inteiramente casualizado, sendo sete períodos de armazenamento $(1,10,20,30,40,50$ e 60 dias), em triplicata. Na análise dos dados, adotou-se estatística descritiva. 


\section{RESULTADOS E DISCUSSÃO}

\section{PRIMEIRO ESTUDO}

Os resultados das análises microbiológicas e dos teores de umidade dos queijos estão representados na Tabela 1.

Tabela 2. Contagens médias de aeróbios mesófilos, coliformes totais, Escherichia coli e teores de umidade de queijos produzidos com leite cru e maturados por 60 dias em condições controladas de umidade e de temperatura.

\begin{tabular}{l|l|l|l|l}
\hline \multirow{2}{*}{ Avaliações } & \multicolumn{2}{|l|}{ Micro-organismos $(\log$ UFC/mL/g } & Teores de \\
\cline { 2 - 5 } & $\begin{array}{l}\text { Aeróbios } \\
\text { mesófilos }\end{array}$ & Coliformes totais & Escherichia coli & umidade (\%) \\
\hline Leite cru & 5,77 & 5,47 & 2,52 & -- \\
\hline Massa & 6,67 & 6,33 & 3,48 & -- \\
\hline $1^{\circ}$ dia & 7,01 & 6,79 & 4,70 & $65 \%$ \\
\hline $10^{\circ}$ dia & 8,56 & 7,73 & 4,89 & $50 \%$ \\
\hline $20^{\circ}$ dia & 8,92 & 7,47 & 5,19 & $33 \%$ \\
\hline $30^{\circ}$ dia & 8,40 & 6,59 & 4,29 & $25 \%$ \\
\hline $40^{\circ}$ dia & 8,07 & 5,87 & 3,83 & $20 \%$ \\
\hline $50^{\circ}$ dia & 7,94 & 6,09 & 3,49 & $19 \%$ \\
\hline $60^{\circ}$ dia & 7,24 & 5,18 & 2,30 & $17 \%$ \\
\hline
\end{tabular}

Os resultados obtidos nas análises físico-químicas do leite cru foram: gordura (4,38\%); ESD $(9,49 \%)$; lactose $(5,55 \%)$; densidade $(1.034 \mathrm{~g} / \mathrm{mL})$; proteínas $(3,22 \%)$; acidez Dornic $\left(18^{\circ} \mathrm{D}\right)$ e crioscopia $\left(-0,542^{\circ} \mathrm{H}\right)$, indicando conformidade com os padrões estabelecidos pela legislação federal para esses parâmetros (BRASIL, 2011). A contagem de aeróbios mesófilos na amostra de leite cru foi de 5,77 $\log \mathrm{UFC} / \mathrm{mL}$ o que reflete desacordo com o critério estabelecido para o leite 
cru refrigerado destinado ao beneficiamento industrial, o qual deve apresentar no máximo 5,48 Log UFC/mL (BRASIL, 2011).

As contagens de aeróbios mesófilos no leite cru apresentaram média de 5,77 log UFC/mL e de 6,67 log UFC/g na massa. Esse aumento é devido à concentração dos constituintes do leite, que agrega também, os micro-organismos durante o processo de coagulação (COSCIANICUNICO et al., 2015). Tal comportamento reforça a importância da qualidade da matéria prima na produção de derivados do leite, em especial de queijos artesanais.

$\mathrm{O}$ aumento nas contagens se manteve até o vigésimo dia de maturação, quando alcançou o valor máximo de 8,92 log UFC/g. Durante esse período, o teor de umidade do queijo passou de 65\% para $33 \%$ indicando que essa alteração não representou um fator limitante para esses microorganismos. A partir do trigésimo dia de maturação observou-se redução para 8,40 log UFC/g sendo que aos 60 dias a contagem de aeróbios mesófilos foi de 7,24 log UFC/g, entretanto, essa contagem ainda foi superior àquela observada na matéria prima.

A redução dos aeróbios mesófilos após o trigésimo dia de maturação pode ter ocorrido devido à redução progressiva da umidade dos queijos (de 25\% no trigésimo dia para $17 \%$ ao final do período) resultando em diminuição da água disponível para o desenvolvimento bacteriano ou, ao acúmulo de metabólitos provenientes da multiplicação dos micro-organismos até o ponto de se tornar limitante para o crescimento dessas bactérias. Todos os micro-organismos necessitam de água, portanto uma das maneiras mais eficientes para controle da atividade metabólica e multiplicação é reduzir a sua disponibilidade, seja por desidratação ou por adição de algum componente solúvel em água, como sais e compostos de baixo peso molecular como ácidos orgânicos. (SOUZA, 2002).

Martins et al. (2015) e das Dores et al. (2013), em trabalhos com queijos artesanais produzidos com leite cru nas regiões do Serro e da Canastra em Minas Gerais descreveram acentuado declínio na contagem de aeróbios mesófilos desde o primeiro até o sexagésimo dia de maturação em condições de temperatura ambiente e sob refrigeração.

Por outro lado, Borges (2015) observou que somente após 40 dias de maturação, em queijo tipo Minas fabricado com leite cru e mantido em temperatura e umidade ambientes, a contagem de aeróbios mesófilos ficou inferior à observada na massa e que, somente após 50 dias a contagem foi menor do que a do leite. 
Durmaz (2009) relatou que não houve redução significativa nas contagens de aeróbios mesófilos durante 90 dias de maturação de queijos artesanais turco e Milani et al. (2014) observaram redução de 0,87 ciclos log na contagem de aeróbios mesófilos durante 60 dias de maturação de queijos artesanais iranianos fabricados com leite cru.

Quanto às contagens de coliformes totais e E. coli observadas no leite cru ( 5,47 UFC/mL e 2,52 UFC/mL, respectivamente) e na massa (6,33 UFC/g e 3,48 UFC/g) também observou-se aumento. Rocha et al. (2006) relataram aumento de 4,5 e 5 ciclos log para coliformes totais e $E$. coli, respectivamente, durante a fabricação de queijos Minas frescal produzido com leite cru.

Os coliformes totais apresentaram contagem média máxima no décimo dia de maturação (7,73 log UFC/g), correspondendo a aumento de 1,4 ciclos log quando comparada à massa e, de 2,26 ciclos log em comparação às contagens obtidas do leite. E. coli apresentou a maior contagem média $(5,19 \log \mathrm{UFC} / \mathrm{g})$ no vigésimo dia, o que representa aumento de 1,71 ciclos log em relação à massa e, 2,67 ciclos log quando comparada à do leite.

Aos 30 dias de maturação as contagens de coliformes totais (6,59 log UFC/g) e de E. coli $(4,29 \log \mathrm{UFC} / \mathrm{g})$ apresentaram redução e ficaram abaixo das observadas no primeiro dia de maturação. Somente aos 60 dias de maturação as contagens de coliformes totais e E. coli ficaram abaixo das encontradas no leite cru (5,18 UFC/g e 2,30 UFC/g, respectivamente) porém, ainda em desacordo com os padrões contidos nas regulamentações na Portaria n 146/1996 (MAPA), e RDC no 12/2001 (ANVISA).

Segundo Borges (2015) bactérias Gram negativas são mais exigentes em relação à atividade de água, do que bactérias Gram positivas e isso pode explicar o declínio das contagens à medida que os teores de umidade dos queijos diminuíam. Aqui também, à semelhança do observado com as contagens de aeróbios mesófilos, o acúmulo de metabólitos provenientes da multiplicação excessiva dos micro-organismos, pode ter influenciado nas reduções das contagens.

Resultados semelhantes foram relatados por Milani et al. (2014) em pesquisa com queijos iranianos artesanais fabricados com leite cru e maturados por 60 dias.

Durante todo o período de maturação, o queijo apresentou aspecto típico, sem alterações de odor ou textura, e manteve-se aparentemente adequado ao consumo, não apresentando crescimento de fungos em sua superfície. Na figura 1 é possível observar o efeito visual da perda de umidade ao longo dos 60 dias de acompanhamento, desde o dia da fabricação (dia 1), em que a umidade era de $65 \%$, até o último dia de maturação (dia 60), em que a umidade chegou a $17 \%$. 


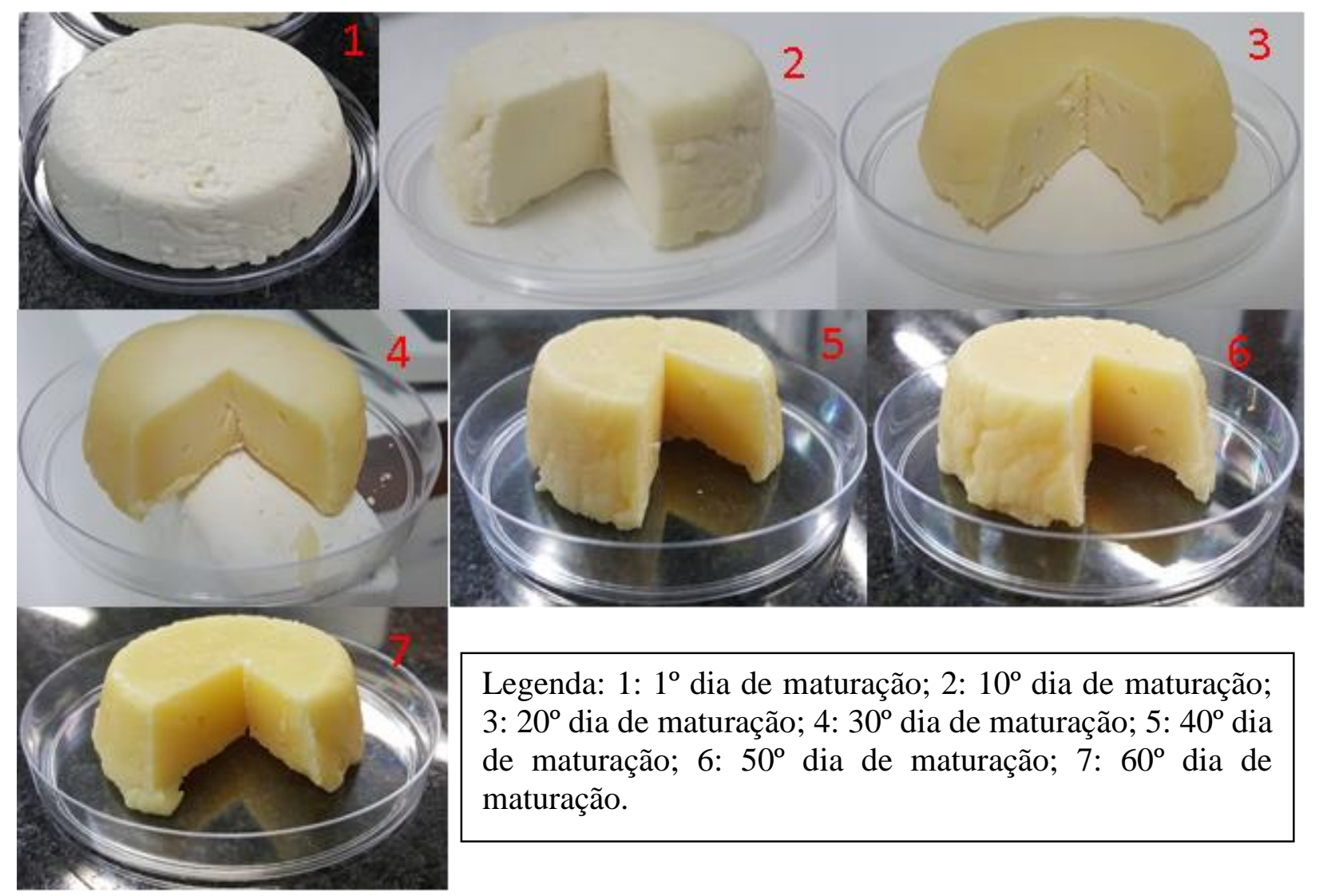

Figura 1. Efeito visual da perda de umidade ao longo dos 60 dias de maturação.

Resultados obtidos em pesquisas com queijos das regiões da Canastra (DORES, 2007; das DORES et al., 2013) e do Serro (MARTINS, 2006; MARTINS et al., 2015) em Minas Gerais Brasil e da região nordeste do Irã (MILANI et al., 2014), demonstraram reduções nas contagens desses micro-organismos desde o primeiro dia de maturação. Por outro lado, Cosciani-Cunico et al. (2015), Durmaz (2009) e Vasek et al. (2013), que trabalharam com queijos artesanias, fabricados com leite cru, italiano, turco e argentino, respectivamente, referem aumento no momento inicial da maturação conforme o encontrado no presente trabalho.

Mello e Armachuk (2013) observaram que o período de maturação de 15 dias não foi suficiente para controlar a contaminação de coliformes termotolerantes em queijos coloniais fabricados e maturados em laticínio de Francisco Beltrão, Paraná.

Já Vasek et al. (2013) concluíram que com 30 dias de maturação há redução da contagem de E. coli para valores abaixo dos encontrados no leite. Na pesquisa de Barros et al. (2008), com queijo parmesão, os autores verificaram redução nas contagens de coliformes totais, inoculados após pasteurização do leite utilizado para fabricação dos queijos, aos 30 e aos 60 dias de maturação. 
Em estudo de avaliação de queijo colonial durante 60 dias de maturação, Mello e Armachuk (2013) constataram que o produto estava próprio para consumo somente aos 30 dias de maturação no que se refere à contagem de coliformes totais e termotolerantes.

Borges (2015) avaliou o efeito do período de maturação por 60 dias, sobre a microbiota naturalmente presente em queijo do tipo Minas produzido com leite cru mantido em condições de temperatura e umidade ambientais, concluindo que esse período foi insuficiente para garantir a qualidade e a inocuidade do queijo. A autora relata que ao final do período de maturação proposto, o teor de umidade do queijo era de $9 \%$.

Em experimento durante a estação seca, Dores et al. (2013) relataram que foram necessários 13 dias de maturação em temperatura de refrifgeração para que o queijo Canastra ficasse em conformidade com a legislação (BRASIL, 1996, 2000) no que se refere a coliformes totais e a $E$. coli. Em condições similares de umidade e temperatura, Martins et al. (2015) registraram a necessidade de apenas 2 dias de maturação de queijo Serro para coliformes totais e E. coli se adequarem à legislação (BRASIL, 1996).

De acordo com a legislação brasileira, é proibida a comercialização de queijos feitos com leite cru com menos de 60 dias de maturação. Porém, de acordo com Martins (2006) e Dores et al. (2012) esses queijos são comercializados, em sua maioria, frescos ou com até 21 dias de maturação em virtude da preferência dos consumidores.Observando os dados do presente experimento, o período até 21 dias de maturação foi o mais crítico em relação às contagens dos micro-organismos analisados, o que representa risco à saúde humana caso esses queijos fossem consumidos.

Rocha et al. (2006), analisando a qualidade de queijo Minas frescal comercializado em São Paulo-SP, também encontraram valores altos para contagem de coliformes totais e E. coli sendo que seis marcas das sete analisadas se encontravam acima do limite máximo permitido pela legislação durante o período de 21 dias de armazenamento.

Mello e Armachuk (2013) concluíram que mesmo com a possível redução dos microorganismos pela maturação o queijo ainda pode oferecer riscos ao consumidor após o período de maturação de 60 dias determinado pela legislação, uma vez que apresenta contaminação por microorganismos capazes de produzir enterotoxinas que podem provocar transtornos alimentares. 


\section{SEGUNDO ESTUDO}

Os resultados das contagens de L. monocytogenes na massa e nos queijos, em relação aos tempos de maturação, assim como os teores de umidade dos queijos estão contidos no Gráfico 1.

Gráfico 1. Contagens de L. monocytogenes (UFC/g) inoculada e teores de umidade (\%) de queijos maturados por 60 dias em condições controladas de umidade e de temperatura.

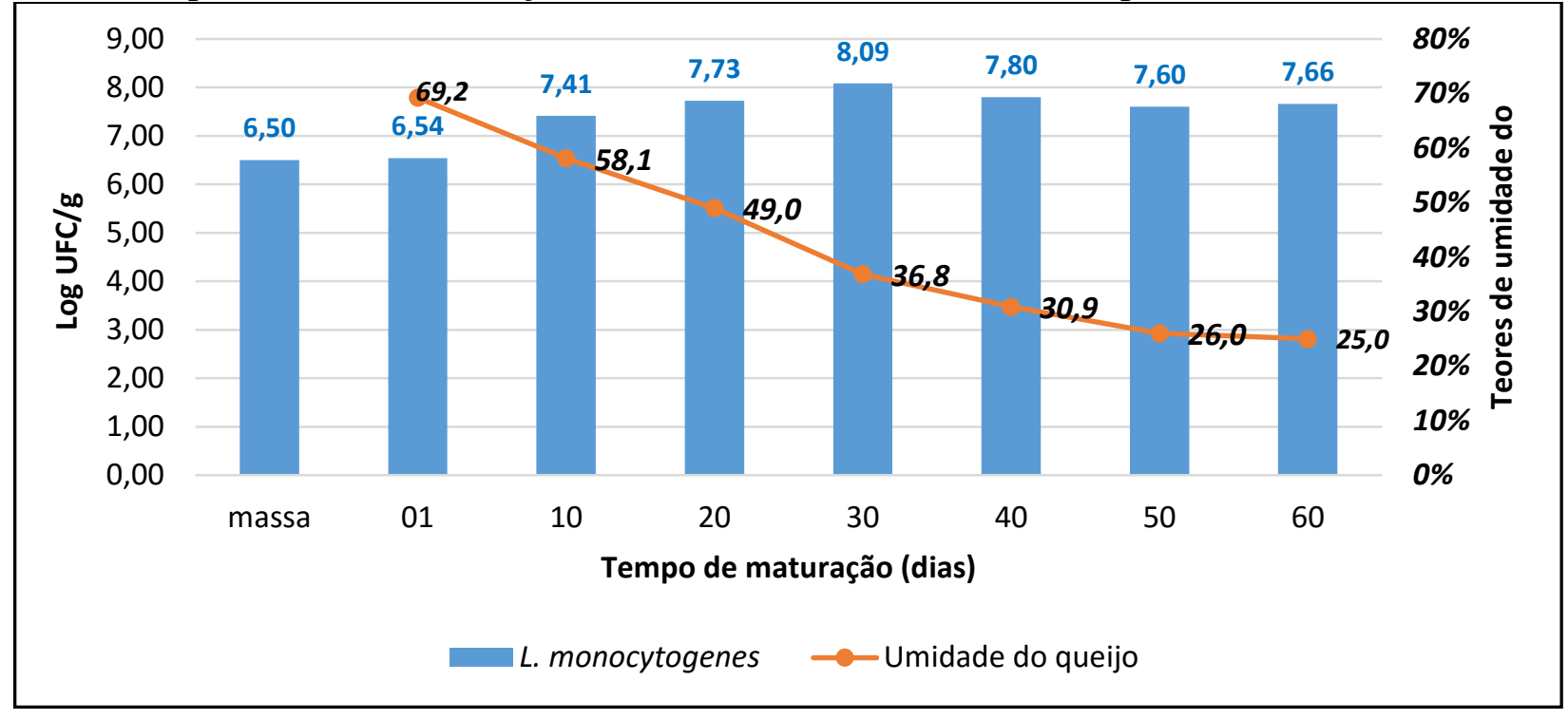

Considerando que as enumerações de L. monocytogenes foram feitas a partir de queijos provenientes da mesma massa, foi observado aumento na contagem em relação à massa (6,5 log UFC/g) até o trigésimo dia de maturação $(8,09 \log \mathrm{UFC} / \mathrm{g})$ representando aumento de 1,59 ciclos $\log$. Aos trinta dias de maturação o teor de umidade era de 36,8\%.

Após o aumento inicial das contagens do micro-organismo observou-se redução nas a partir do $40^{\circ}$ dia de maturação $(7,80 \log \mathrm{UFC} / \mathrm{g})$ quando o teor de umidade era de $30,9 \%$. No $50^{\circ}$ dia as contagens e a umidade foram de 7,60 log UFC/g e de 30,9\%, respectivamente. Aos 60 dias de maturação a contagem de $L$. monocytogenes não seguiu a mesma tendência de redução, observando-se, inclusive, um discreto aumento no valor (7,66 log UFC/g).

Ao final do período de maturação, as contagens ainda eram de 1,16 ciclos log acima da contagem inicial, com o queijo apresentando $25 \%$ de umidade, demonstrando persistência da contaminação dos queijos durante o período de maturação. Isso confirma a capacidade da bactéria em se desenvolver em temperaturas de refrigeração, o que é preocupante tendo em vista que queijos de muita alta, alta e médias umidades, devem ser mantidos refrigerados até o final do consumo. Como L. monocytogenes cresce em produtos lácteos, principalmente queijos de média e alta 
umidade, ainda que armazenados por longos períodos em temperatura de refrigeração (BARANCELLI et al., 2011a), o consumo de queijos fabricados com leite cru pode expor o consumidor ao micro-organismo.

Corroborando com o presente trabalho, Cosciani-Cunico et al. (2015) em estudos com queijos artesanais na Itália, observaram que em sessenta dias de maturação sob refrigeração (4 a $5^{\circ} \mathrm{C}$ ) não houve redução nas contagens de L. monocytogenes, e em tempos de maturação mais longos (120 dias) e sob refrigeração $\left(12^{\circ} \mathrm{C}\right)$ também não houve redução significativa do microorganismo. Os autores também destacam que a presença de contaminação por bactérias patogênicas, mesmo que em baixas contagens, no leite destinado a produção de queijos com leite cru constitui uma ameaça à saúde do consumidor, pois ocorre grande aumento na concentração e multiplicação das bactérias durante a produção e maturação dos queijos.

Naldini et al. (2009) sugerem que a utilização de temperatura de $10^{\circ} \mathrm{C}$ para armazenamento produz um aumento na velocidade de multiplicação de L. monocytogenes, mas que a produção de ácido láctico por bactérias ácido láticas é um fator importante no controle do crescimento do patógeno; em conjunto com a competição por nutrientes, pode-se inferir que a adição de culturas starters funciona como um inibidor desta bactéria, e que, quando completamente removidas da fabricação, facilita o seu desenvolvimento.

Por outro lado, Durmaz (2009), em experimentos com queijos artesanais na Turquia, relata aumento na contagem de L. monocytogenes de aproximadamente 2,0 ciclos log na fabricação do queijo, após a coagulação do leite inoculado com o micro-organismo. O autor observou redução de aproximadamente 0,7 ciclos log após 15 dias de maturação e manutenção das contagens durante os outros 75 dias de maturação apesar do baixo pH e de elevado número de bactérias ácido láticas.

Conforme Serraino et al. (2013) em trabalho com mussarela de búfala espera-se que com baixa contaminação do leite não haja replicação significativa de L. monocytogenes durante o período de maturação, o que não representaria risco à saúde, porém em alimentos que oferecem condições para a multiplicação a bactéria poderia atingir altas contagens durante o armazenamento prolongado sob refrigeração (ILSI, 2005).

A variação na ocorrência da L. monocytogenes em queijos pode ser explicada pelo uso de diferentes métodos para a detecção da bactéria, diferenças de padrões de qualidade dos queijos e pelo uso de leite cru ou pasteurizado como matéria-prima. Os coliformes parecem exercer influência na população desse patógeno em queijo Minas frescal impedindo sua proliferação, 
podendo inclusive dificultar sua detecção (ARAGON-ALEGRO et al., 2006), assim como as bactérias ácido láticas também podem influenciar no comportamento de L. monocytogenes (NALDINI et al., 2009; NERO et al., 2009).

Espinoza et al. (2004) constataram a incidência de L. monocytogenes em 4\% das amostras de queijos artesanais frescos comercializados em mercados da região de Lima, Peru, e ressaltaram a possibilidade de ocorrer contaminação cruzada em queijos com ausência da bactéria, o que representa risco à saúde do consumidor.

No que se refere aos requisitos microbiológicos de queijos de baixa umidade (umidade menor que 36\%) tem grande relevância questionar a lacuna na legislação brasileira (BRASIL, 1996) quanto à necessidade de se estabelecer limites microbiológicos para L. monocytogenes também para queijos com menos de $36 \%$ de umidade, uma vez que essa bactéria tem resistência a baixa umidade e temperatura, permanecendo viável por longos períodos de maturação.

Vinha (2009) relata a presença de Listeria spp. em queijos Minas frescal de fabricação industrial e artesanal (67\% das agroindústrias pesquisadas), sendo que 14\% das amostras estavam contaminadas com L. monocytogenes demonstrando o risco potencial do consumo de queijo Minas frescal produzido principalmente de forma artesanal e sem qualquer tipo de inspeção.

Além disso, deve-se ressaltar que em ambientes de preparação dos derivados lácteos a bactéria pode estar presente, apesar de muitas vezes não ser possível o seu isolamento de amostras de leite cru devido à competição com outros micro-organismos, à distribuição irregular da bactéria quando se analisa grandes volumes de leite ou aos baixos níveis de contaminação (BARANCELLI et al, 2011b).

A garantia da inocuidade dos produtos de fabricação tanto artesanal quanto industrial é imprescindível para a manutenção das atividades e para evitar possíveis surtos de doenças causadas por alimentos contaminados por micro-organismos patogênicos, principalmente por $L$. monocytogenes pela gravidade da patogenia. Assim, ao mesmo tempo em que a valorização de alimentos tradicionais tem sido apontada como estratégica para a continuidade de áreas rurais, a comercialização desses produtos em mercados formais requer que sejam definidos critérios em termos de estrutura e segurança alimentar, sendo urgente a definição de parâmetros microbiológicos que atendam tanto a capacidade dos produtores quanto a segurança dos consumidores. 


\section{CONCLUSÕES}

Os resultados obtidos permitem concluir que o período de 60 dias de maturação de queijos produzidos com leite cru, nas condições propostas por esta pesquisa, é insuficiente para garantir a qualidade higiênico-sanitária do alimento tendo em vista as altas contagens de micro-organismos aeróbios mesófilos, coliformes totais e Escherichia coli constatadas ao final da maturação.

A persistência de Listeria monocytogenes inoculada na massa dos queijos, mesmo quando em baixos teores de umidade, representa elevado risco à saúde dos consumidores sendo importante uma revisão da legislação vigente, para que possam ser reavaliados os limites microbiológicos para essa bactéria para queijos com baixos teores de umidade.

Finalmente, os dados apresentados reafirmam a importância da qualidade da matéria-prima na fabricação de derivados lácteos e, corroboram a decisão dos órgãos de fiscalização brasileiros, quanto à exigência de avaliar e consolidar dados científicos provenientes de pesquisas, que possam subsidiar decisões referentes à produção de queijos produzidos com leite cru, sempre com o objetivo de garantir a saúde dos consumidores. 


\section{REFERÊNCIAS BIBLIOGRÁFICAS}

AMORIM A. L. B. C.; COUTO E. P.; SANTANA A. P.; RIBEIRO J. L.; FERREIRA M. A. Avaliação da qualidade microbiológica de queijos do tipo Minas padrão de produção industrial, artesanal e informal. Rev Inst Adolfo Lutz. São Paulo, v. 73, n. 4, p. 364-367, oct. 2014.

ANTONELLO, L., KUPKOVSKI, A., BRAVO C. C. Qualidade microbiológica de queijos coloniais comercializados em Francisco Beltrão, Paraná. Revista Thema, 2012.

APHA. American Journal of Public Health and the Nations Health. Cheese and Its Relation to Disease. August 1947, Vol 37, No. 8, pp. 987-996. 1947.

ARAGON-ALEGRO, L.C.; SOUZA, K.L.O.; NUNES T.P.; LANDGRAF, M.; FRANCO, B.D.G.M.; DESTRO, M.T. Influência de coliformes na população de Listeria monocytogenes em queijo Minas frescal. In: CONGRESSO BRASILEIRO DE CIÊNCIA E TECNOLOGIA DE ALIMENTOS, 10., 2006, Curitiba. Anais. Campinas: SBCTA, 2006.

ARRUDA, M. L. T. Ocorrência de Staphylococcus coagulase positiva em queijos Minas Frescal e Padrão de feiras livre de Goiânia - GO e detecção de genes produtores de enterotoxinas A e B por meio da técnica de duplex PCR. Dissertação de mestrado em Ciência Animal junto à Escola de Veterinária da Universidade Federal de Goiás, 2006.

BARANCElli, G. V., CAMARGO, T. M., REIS, C. M. F., PORTO, E., HOFER, E. E OLIVEIRA, C. A. F. Incidence of Listeria monocytogenes in Cheese Manufacturing Plants from the Northeast Region of Sao Paulo, Brazil. Journal of Food Protection, Vol. 74, No. 5, Pages 816-819. $2011 \mathrm{~b}$.

BARANCELLI, G.V., SILVA-CRUZ, J.V., PORTO, E. E OLIVEIRA, C.A.F. Listeria monocytogenes: ocorrência em produtos lácteos e suas implicações em saúde pública. Arq. Inst. Biol., São Paulo, v.78, n.1, p.155-168, jan./mar., 2011a.

BARCELLOS, T. G. Pesquisa de E. coli em queijo Minas frescal oriundos de feiras no Distrito Federal. Monografia - curso de qualidade em alimentos. Brasilia - DF, março de 2006.

BARROS, J. J. C., AZEVEDO, A. C., ROSSI, D. A., MOURA, C. J. e PENNA, A. L. B. Avaliação do aspecto sanitário e microbiota lática durante a maturação do queijo parmesão. Rev. Inst. Latic. Cândido Tostes Set/Out, No 364, 63 : 27-35, 2008. 
BORGES, L.C. Efeitos do processo de maturação sobre a microbiota autóctone de queijo produzido com leite cru. Monografia - Universidade de Brasília / Faculdade de Agronomia e Medicina Veterinária, 26 p. 2015.

BORGES, M. F.; FEITOSA, T.; NASSU, R. T.; AZEVEDO, E. H. F.; MUNIZ, C. R. Análise microbiológica de queijos produzidos no Estado do Rio Grande do Norte. Ciênc. Tecnol. Aliment., Campinas, 23(Supl): 162-165, dez. 2003.

BRANT, L. M. F., FONSECA, L. M., SILVA, M. C. C. Avaliação da qualidade microbiológica do queijo-de-Minas artesanal do Serro-MG. Arq. Bras. Med. Vet. Zootec. vol.59 no.6 Belo Horizonte Dec. 2007.

BRASIL. Ministério da Agricultura, Pecuária e Abastecimento - MAPA. Portaria n ${ }^{\circ} 146$ de 07 de março de 1996. Aprova os Regulamentos Técnicos de Identidade e Qualidade dos Produtos Lácteos. Diário Oficial da República Federativa do Brasil, Brasília, 07 mar. 1996.

BRASIL. Ministério da Agricultura, Pecuária e Abastecimento (MAPA). Instrução Normativa $n^{\circ}$ 62 de 29 de dezembro de 2011. Aprova o Regulamento Técnico de Produção, Identidade e Qualidade do Leite tipo A, o Regulamento Técnico de Identidade e Qualidade de Leite Cru Refrigerado, o Regulamento Técnico de Identidade e Qualidade de Leite Pasteurizado e o Regulamento Técnico da Coleta de Leite Cru Refrigerado e seu Transporte a Granel. Diário Oficial da União, Brasília, DF, Seção 1, p. 6. 31 de dez, 2011.

BRASIL. Ministério da Agricultura, Pecuária e Abastecimento. Instrução Normativa no 68 de 14 de dezembro de 2006. Oficializa os Métodos Analíticos Oficiais Físico-Químicos, para Controle de Leite e Produtos Lácteos, em conformidade com o anexo desta Instrução Normativa, determinando que sejam utilizados nos Laboratórios Nacionais Agropecuários. Diário Oficial da União, Brasília, 14 dez. 2006.

BRASIL. Ministério da Agricultura, Pecuária e Abastecimento. Resolução n ${ }^{\circ}$ 7, de 28 de novembro de 2000. Critérios de funcionamento e de controle da produção de queijarias, para seu relacionamento junto ao serviço de inspeção federal. Diário Oficial da República Federativa do Brasil, Brasília, DF, nov. 2000.

BRASIL. Ministério da Saúde. Agência Nacional de Vigilância Sanitária. Resolução - RDC no 12, de 2 de janeiro de 2001. Regulamento técnico sobre os padrões microbiológicos para alimentos. Brasília, 2001.

CASTRO, R. D. Queijo Minas artesanal fresco de produtores não cadastrados da mesorregião de Campo das Vertentes - MG: qualidade microbiológica e físico-química em diferentes épocas do ano. Dissertação (mestrado) - Universidade Federal de Minas Gerais, Escola de Veterinária. 125 p. 2015.

CENTERS FOR DISEASE CONTROL AND PREVENTION (CDC). Surveillance for Foodborne Disease Outbreaks, United States, 2013, Annual Report. Atlanta, Georgia: US Department of Health and Human Services, CDC, 2015. 
COSCIANI-CUNICO, E., DALZINI, E., DUCOLI, S., SFAMENI, C., BERTASI, B., LOSIO, M., DAMINELLI, P. E VARISCO, G. Behaviour of Listeria monocytogenes and Escherichia coli O157:H7 during the cheese making of traditional raw-milk cheeses from Italian Alps. Italian Journal of Food Safety Vol 4, No 3. 2015.

CRUZ, C. D., MARTINEZ, M. B., DESTRO, M. T. Listeria monocytogenes: um agente infeccioso ainda pouco conhecido no Brasil. Alim. Nutr. Araraquara, v. 19, no. 2, p. 195-206, abr./ jun. 2008.

DORES, M. T DAS., \& FERREIRA, C. L. L. F. Queijo Minas artesanal, tradição centenária: ameaças e desafios. Revista Brasileira de Agropecuária Sustentável (RBAS), v.2, n.2, p. 26-34. Dez 2012.

DORES, M. T. DAS., NOBREGA, J. E., FERREIRA, C. L. L. F. Room temperature aging to guarantee microbiological safety of brazilian artisan Canastra cheese. Food Sci. Technol, Campinas, 33(1): 180-185, Jan.-Mar. 2013.

DORES, M. T. DAS., Queijo Minas arntesanal da Canastra maturado à temperatura ambiente e sob refrigeração. Viçosa: UFV, 91f. : il. 2007.

DURMAZ, H. Fate of Listeria monocytogenes in carra cheese during manufacture and ripening. Journal of Food Safety 29, 253-260. 2009.

ESPINOZA A. M., DE LA TORRE M. B., SALINAS M. F. E SÁNCHEZ V. P. Determinación de Listeria monocytogenes en quesos frescos de producción artesanal que se expenden en los mercados del distrito de Ica, enero - marzo 2003. Rev peru med exp salud publica 21(2), 2004.

FEITOSA, T.; BORGES, M. F.; NASSU, R. T.; AZEVEDO, É. H. F.; MUNIZ, C. R. Pesquisa de Salmonella sp., Listeria sp. e micro-organismos indicadores higiênico-sanitários em queijos produzidos no estado do Rio Grande do Norte. Ciênc. Tecnol. Aliment. vol.23 suppl.0 Campinas Dec. 2003.

FERNANDES, R. V. B., BOTREL, D. A., ROCHA, V. V., SOUZA, V. R., CAMPOS, F. M., MENDES, F. Q. Avaliação físico-química, microbiológica e microscópica do queijo artesanal comercializado em Rio Paranaíba - MG. Rev. Inst. Latic. "Cândido Tostes", Set/Out, n” 382, 66: 21-26, 2011.

FEUTRY, F.; ONECA, M.; BERTHIER, F. et al. Biodiversity and growth dynamics of lactic acid bacteria in artisanal PDO Ossau-Iraty cheeses made from raw ewe's milk with different starters. Food Microbiol., v. 29, n. 1, p. 33-42, 2012.

GONZÁLEZ, J., MAS, M., TABLA, R. et al. Autochthonous starter effect on the microbiological, physicochemical and sensorial characteristics of Ibores goat's milk cheeses. Le Lait., v. 83, n. 3, p. 193-202, 2003.

GOULD, L. H.; MUNGAI E. A.; BEHRAVESH C. B. Outbreaks Attributed to Cheese: Differences Between Outbreaks Caused by Unpasteurized and Pasteurized Dairy Products, United States, 19982011. Foodborne Pathogens and Disease. July 2014, v.11, n.7, p. 545-551. 
IAL (INSTITUTO ADOLFO LUTZ). Métodos físico-químicos para análise de alimentos. 4 ed. 1 ed. digital. Cap. 4. 2004.

ILSI. Research foundation/risk science institute, expert panel on Listeria monocytogenes in foods. Achieving continous improvement in reduction in foodborne listeriosis - a risk based approach. Journal of Food Protection, v.68, n.9, p.1932-1994, 2005.

JAY, J. M. Microbiologia de alimentos. 6 ed., Porto Alegre, Artmedia. 711p. 2005.

LAW, B. A.; TAMIME, A. Y. Technology of cheesemaking. Sussex: Wiley-Blackwell, 515 p. 2010.

LEITE, B. M. Aspectos epidemiológicos e econômicos da certificação de propriedades leiteiras como livres de brucelose e tuberculose bovina. Dissertação de mestrado em saúde animal, Universidade de Brasília. 2012.

MACHADO, P. F. Pagamento do Leite por Qualidade. In CONGRESSO BRASILEIRO DE QUALIDADE DO LEITE 3., 2008, Recife: CCS Gráfica e Editora, 373 p. 2008.

MAGALHÃES, V. C. Avaliação da qualidade microbiológica de amostras de leite e queijo analisadas no laboratório GMO durante o $2^{\circ}$ semestre de 2006. Monografia apresentada ao Programa de Pós- Graduação em Microbiologia do Instituto de Ciências Biológicas da Universidade Federal de Minas Gerais. Belo Horizonte - MG. 2007.

MARTINS, J. M. Características físico-químicas e microbiológicas durante a maturação do queijo Minas artesanal da região do serro. Viçosa: UFV, 158f. : il. 2006.

MARTINS, J. M., GALINARI, É., PIMENTEL-FILHO, N. J., RIBEIRO JR, J. I., FURTADO, M. M., \& FERREIRA, C. L. Determining the minimum ripening time of artisanal Minas cheese, a traditional Brazilian cheese. Brazilian Journal of Microbiology, v.46, n.1, p. 219-230. 2015.

MELLO, E. Z., ARMACHUK, M. A. Avaliação das mudanças ocorridas no Queijo Colonial durante a maturação: modificações físico-químicas e microbiológicas. 2013. 79 f. Trabalho de conclusão de curso (Curso Superior em Tecnologia em Alimentos) - Universidade Tecnológica Federal do Paraná. Francisco Beltrão, 2013.

MELO, A. C. M., ALVES, L. M. C., COSTA F. N. Avaliação da qualidade microbiológica do queijo tipo Minas padrão comercializado na cidade de São Luis, MA. Arq. Inst. Biol., São Paulo, v.76, n.4, p.547-551, out./dez., 2009.

MENESES, R. B.; CARDOSO, R. C. V.; GUIMARÃES, A. G.; GÓES, J. A. W.; SILVA, S. A.; ARGOLO, S. V. O comércio de queijo de coalho na orla de Salvador, Bahia: trabalho infantil e segurança de alimentos. Revista de Nutrição, Campinas, v. 25, n. 3, p. 381-392, Junho 2012.

MILANI, E., SHAHIDI, F., MORTAZAVI, S. A., VAKILI, S. A. R. e GHODDUSI, H. B. Microbiological, biochemical and rheological changes throughout ripening of kurdish cheese. Journal of Food Safety 34 (2014) 168-175 @ 2014. 
MINAS GERAIS. Lei $n^{\text {o }} 14.185 / 2002$ de 31 de Janeiro de 2002. Dispõe sobre o processo de produção do queijo Minas artesanal e dá outras providências. Diário do Executivo. 31 de jan. 2002.

MINAS GERAIS. Lei n ${ }^{\circ}$ 20549, de 18 de dezembro de 2012. Dispõe sobre a produção e a comercialização dos queijos Artesanais de Minas Gerais. Diário do Executivo. 19 de dez. 2012.

MINAS GERAIS. Portaria n ${ }^{\circ}$ 1305, de 30 de abril de 2013 do Instituto Mineiro de Agropecuária (IMA). Estabelece diretrizes para a produção do queijo Minas artesanal. Diário Oficial do Executivo. 1 de mar. 2013.

MUNGAI, E. A.; BEHRAVESH, C. B.; GOULD, L. H. Increased outbreaks associated with nonpasteurized milk, United States, 2007-2012. Emerging Infectious Diseases [Internet]. v. 21, n. 1, Janeiro 2015.

NALDINI, M.C.M., VIOTTO, W. H. E KUAYE, A. Y. Behaviour of Listeria monocytogenes inoculated into Minas Frescal cheese made by direct acidification or lactic culture during refrigerated storage. International Journal of Dairy Technology Vol 62, No 3 August 2009.

NERO, L. A.; MATTOS, M. R.; BELOTI, V.; BARROS, M. A. F.; ORTOLANI, M. B. T.; FRANCO, B. D. G. M. Autochthonous microbiota of raw milk with antagonistic activity against Listeria monocytogenes and Salmonella Enteritidis. Journal of Food Safety, New Brunswick, v. 29, n. 2, p. 261-270, maio 2009

ORDÓÑEZ, J.A. Tecnologia de Alimentos. Alimentos de origem animal. 1. ed. Porto Alegre: Artmed, v.2, 2005.

PINTO, A. F. M. A. Doenças de origem microbiana transmitidas pelos alimentos. Millenium, 4:91-100. 1996.

PINTO, M. S.; FERREIRA, C. L. L. F.; MARTINS, J. M.; TEODORO, V. A. M.; PIRES, A. C. S.; FONTES, L. B. A.; VARGAS, P. I. R. Segurança alimentar do queijo Minas Artesanal do Serro, Minas Gerais, em função da adoção de boas praticas de fabricação. Pesq. Agropec. Trop., Goiânia, v. 39, n. 4, p. 342-347, out./dez. 2009.

RESENDE, M. F. S. Queijo Minas artesanal da Serra da Canastra: influência da altitude e do nível de cadastramento das queijarias nas características físico - químicas e microbiológicas. Belo Horizonte Escola de Veterinária da UFMG. Dissertação (mestrado) - Universidade Federal de Minas Gerais, Escola de Veterinária. 2010.

ROCHA, J. S.; BURITI, F. C. A.; SAAD, S. M. I. Condições de processamento e comercialização de queijo-de-Minas frescal. Arq. Bras. Med. Vet. Zootec., v.58, n.2, p.263-272, 2006.

SCHMITT, C. I., CERESER, N. D., BOHRZ, D. A. S., NOSKOSKI, L. Contaminação do queijo colonial de produção artesanal comercializado em mercados varejistas do Rio Grande do Sul. Vet. Not., Uberlândia, v.17. n.2, p. 111-116, jul./dez. 2011.

SENGER, A. E. V., BIZANI, D. Pesquisa de Staphylococcus aureus em queijo Minas Frescal, 
produzido de forma artesanal e industrial, comercializado na cidade de Canoas/RS, Brasil. Revista de Ciências Ambientais, Canoas, v.5, n.2, p. 25 a 42, ISSN 1981-8858. 2011.

SERRAINO, A., FINAZZI, G., MARCHETTI, G., DAMINELLI, P., RIU, R., GIACOMETTI, F., LOSIO, M. N. e ROSMINI, R. Fate of Listeria monocytogenes during production and storage of artisan water buffalo mozzarella cheese. Ital. J. Food Sci., vol. 25 - 2013.

SOARES, D. B. Caracterização físico-química e microbiológica do queijo Minas artesanal na região de Uberlândia - MG. Dissertação (mestrado) - Universidade Federal de Uberlândia, 124 p. 2014.

SOUZA, C. F. V. Evolução das características microbiológicas durante a elaboração e maturação do queijo Serrano. Dissertação de Mestrado em Microbiologia Agrícola e do Ambiente, Faculdade de Agronomia, Univerdidade Federal do Rio Grande do Sul, Porto Alegre (139 p.) Março, 2002.

VASEK, O. M., MAZZA, S. M. e GIORI, G. S. Physicochemical and microbiological evaluation of corrientes artisanal cheese during ripening. Food Sci. Technol, Campinas, 33(1): 151-160, Jan.Mar. 2013.

VINHA, M. B. Condições de produção, de comercialização e qualidade higiênico-sanitária do queijo Minas frescal produzido em agroindústrias familiares do município de Viçosa. 121p. Dissertação (Mestrado) - Universidade Federal de Viçosa - MG, Viçosa, 2009. 